\title{
Manifestation of Nonplanarity Effects and Charge-Transfer Interactions in Spectral and Kinetic Properties of Triplet States of Sterically Strained Octaethylporphyrins
}

\author{
V. N. Knyukshto, E. I. Sagun, A. M. Shul'ga, S. M. Bachilo, \\ D. A. Starukhin, and É. I. Zen'kevich \\ Institute of Molecular and Atomic Physics, National Academy of Sciences of Belarus, Minsk, 220072 Belarus \\ Received March 30, 2000
}

\begin{abstract}
Properties of the triplet states of octaethylporphyrins with the steric hindrance (free bases and Pd complexes) are studied by the methods of stationary and kinetic spectroscopy in the temperature range from 77 to $293 \mathrm{~K}$. The mono-mesophenyl substitution results in a decrease in the quantum yield and shortening of the phosphorescence lifetime of Pd complexes by 250-3500 times in degassed toluene at $293 \mathrm{~K}$. The phosphorescence quenching is caused by nonplanar dynamic conformations of the porphyrin macrocycle in the $T_{1}$ state, which also lead to the appearance of new bands at $\lambda \sim 1000 \mathrm{~nm}$ in the $T-T$ absorption spectra. As the number of meso-phenyls (Pd-octaetyltetraphenylporphyrin) increases, the quantum yield of phosphorescence further decreases $\left(<10^{-5}\right)$ at $293 \mathrm{~K}$, the lifetime of the $T_{1}$ state shortens $(<50 \mathrm{~ns})$, and the efficiency of the singlet oxygen generation abruptly decreases $(<0.01)$. The intense bathochromic emission of this compound at $705 \mathrm{~nm}$ with a lifetime of $1 \mathrm{~ms}$ at $77 \mathrm{~K}$ is assigned to the phosphorescence of a nonplanar conformation. Upon meso-orthonitrophenyl substitution, the quenching of phosphorescence of Pd complexes (by more than $10^{4}$ times at $293 \mathrm{~K}$ ) is caused by direct nonadiabatic photoinduced electron transfer from the $T_{1}$ state to the nearest charge-transfer state with the probability $k_{\text {et }}^{T}=(1.5-4.0) \times 10^{6} \mathrm{~s}^{-1}$. The induced absorption of ortho-nitro derivatives in the region between 110 and $1400 \mathrm{~nm}$ is caused by mixing of pure $\pi \pi^{*}$ states with charge-transfer states. (C) 2001 MAIK "Nauka/Interperiodica".
\end{abstract}

\section{INTRODUCTION}

Recent spectral, kinetic, and physicochemical studies [1-4] showed that a number of "hybrid" porphyrins with the steric hindrance (free bases and complexes with metals $\mathrm{Ni}, \mathrm{Cu}$, and $\mathrm{Fe}$ ) have the nonplanar porphyrin macrocycle in the initial $S_{0}$ state, which is manifested in a considerable change in the absorption spectrum (strong bathochromic shift and broadening of the bands) and in redox properties compared to planar tetrapyrrole macrocycles. Upon excitation of such molecules, the dynamic conformational mobility of the tetrapyrrole macrocycle in the $S_{1}$ state is manifested in strong deformations of the fluorescence spectra (bathochromic shift and broadening of the bands, an increase in the Stokes shift) and in a strong decrease in the quantum yield $\varphi_{F}$ and shortening of the fluorescence lifetime $\tau_{s}$. However, at present there is no detailed information on spectral and kinetic parameters of the $T_{1}$ states of hybrid porphyrins under the conditions of dynamic conformational lability of the porphyrin macrocycle in liquid solutions at $293 \mathrm{~K}$. The data available are scarce and are often indirect. Thus, in experiments on bleaching of the absorption bands of porphyrins with the steric hindrance (saddle and ruffle conformations), the quantum yields of the $S_{1} \leadsto T_{1}$ intersystem crossing were estimated to be $\gamma=0.2-0.7$, the lowest values being typical for the ruffle structures [5-9]. In some cases, differential spectra of the induced absorption have been obtained in the region from 600 to $900 \mathrm{~nm}$ upon picosecond excitation [5, 8, 9]. Direct experimental data on the decay of the triplet states for two types of nonplanar tetra-substituted porphyrins are presented in the only paper [9] known to us, where it was shown that, along with a decrease in the quantum yield of intersystem crossing, the lifetime $\tau_{T}$ of the $T_{1}$ state greatly shortened at room temperature in deoxygenated solutions and the quantum yield $\gamma_{\Delta}$ of the singlet oxygen generation decreased. It was found that, for these compounds, $\gamma_{\Delta}<\gamma$, whereas, for usual porphyrins, $\gamma_{\Delta} \cong \gamma[10,11]$.

Recently we found [12-14] that the introduction of even one phenyl ring into the meso position of $\beta$-alkylsubstituted porphyrins [octaethylporphyrins (OEPs), ethioporphyrin II, and their $\mathrm{Zn}$ complexes] results in a drastic shortening of $\tau_{T}$ at room temperature in liquid solutions and virtually does not affect the spectral and kinetic parameters of the $S_{1}$ state decay. We showed in these papers that this effect is related to torsion vibrations (librations) of the phenyl ring around a single $\mathrm{C}-\mathrm{C}$ bond in porphyrins with the steric hindrance. As a result, the nonplanar dynamic conformations of the tet- 


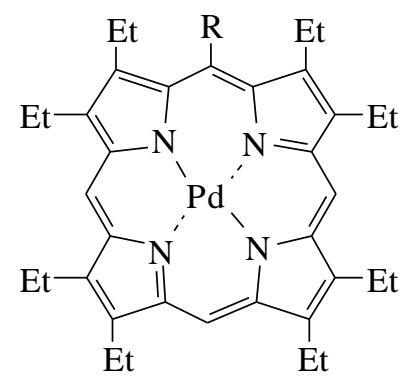

1: $\mathrm{R}=\mathrm{H}$<smiles></smiles>

3: $\mathrm{R}=-\mathrm{CH}_{3}$

6: $\mathrm{R}$<smiles>N#Cc1ccccc1[N+](=O)[O-]</smiles>

4:

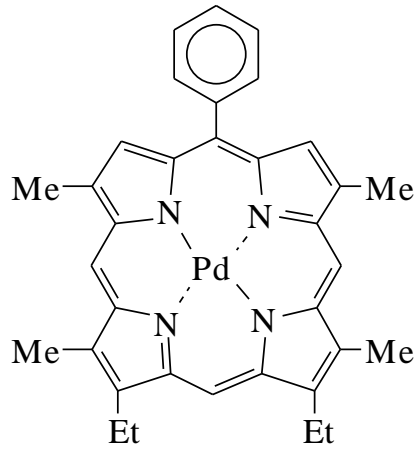

$5:$

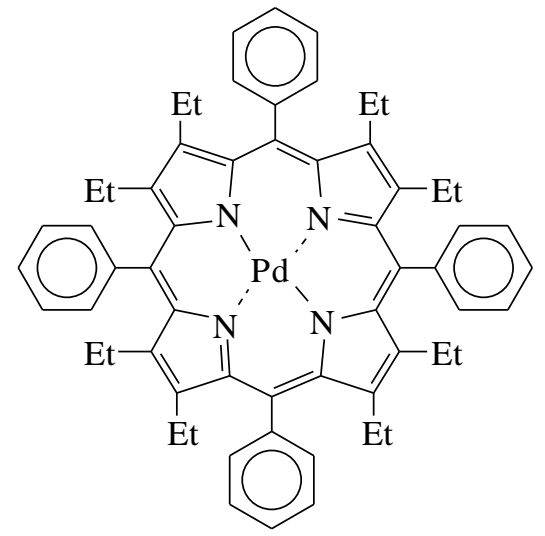

Fig. 1. Structural formulas of molecules studied and their abbreviations. (1) 2,3,7,8,12,13,17,18-octaethylporhyrinato-Pd(II), PdOEP; (2) 5-phenyl-2,3,7,8,12,13,17,18octaethylporhyrinato-Pd(II), PdOEP-Ph; (3) 5-methyl$2,3,7,8,12,13,17,18$ - octaethylporhyrinato-Pd(II), PdOEP$\mathrm{CH}_{3}$; (4) 5-phenyl-2,8,12,18-tetramethyl-13,17-diethylporphyrinato-Pd(II), PdTMDEP-Ph; (5) 2,3,7,8,12,13,17,18octaetyl-5,10,15,20-tetraphenylporphyrinato-Pd(II), PdOETPP; (6) 5-(ortho-nitrophenyl)-2,3,7,8,12,13,17,18-octaethylporphyrinato-Pd(II), $\left.\mathrm{PdOEP}-\mathrm{Ph}\left(o-\mathrm{NO}_{2}\right)\right)$.

rapyrrole macrocycle appear in the excited $T_{1}$ state in which nonradiative intersystem crossing is activated (an increase in the $T_{1}$ level energy, a decrease in the overlap integrals for the $n$ orbitals of nitrogen and $\pi$ orbitals of the macrocycle upon the displacement of nitrogen atoms from the macrocycle plane, and activation of new types of accepting modes).

Note in this connection that the most convenient objects for a detailed study of spectral manifestations of the conformational dynamics of porphyrins with the steric hindrance in the $T_{1}$ state are the Pd complexes. They were chosen for the study for a number of reasons. Palladium complexes of porphyrins have high quantum yields of the $S_{1} \leadsto T_{1}$ intersystem crossing $(\gamma \approx 1[15])$ and the $T_{1} \longrightarrow S_{0}$ phosphorescence $\left(\varphi_{P} \approx\right.$ $0.1-0.5[16-18])$ both at room and low temperature. Therefore, a simultaneous analysis of the data on spectral and kinetic properties of the induced $T-T$ absorption and phosphorescence at $293 \mathrm{~K}$ allows one to obtain detailed information on the mechanisms of dynamic relaxation of the $T_{1}$ states of porphyrins with the steric hindrance.

In addition, because of the high probability of the $S_{1} \leadsto T_{1}$ intersystem crossing $\left(r=8.3 \times 10^{10} \mathrm{~s}^{-1}[19]\right)$, Pd porphyrins are attractive for the study of photoinduced electron transfer (PET) involving triplet states. Such an approach was used for studying PET from the $T_{1}$ state in covalently bonded complexes of Pd-tetraphenylporphyrin-quinone (PdTPP-Q) in toluene at $293 \mathrm{~K}$ [19]. We have shown that efficient PET (the probability $k_{\text {et }}^{S}=9.5 \times 10^{9} \mathrm{~s}^{-1}$ in toluene at $293 \mathrm{~K}$ ) occurs from the excited $S_{1}$ states of steric hindered meso-ortho-nitrophenyloctaetylporphyrins and their chemical dimers to the $\mathrm{NO}_{2}$ group, which can be described by the Marcus theory for nonadiabatic electron transfer [20-22]. The study of Pd complexes of these compounds is of interest from the point of view of the elucidation of mechanisms of PET involving triplet states.

In this work, we performed a comparative experimental study of spectral and kinetic parameters of molecules of PdOEP, PdOEP- $\mathrm{CH}_{3}$, and PdTMDEP-Ph, which are not subject to the conformational rearrangement in the $T_{1}$ state or their steric hindered meso-phenyl-substituted analogs PdOEP-Ph and PdOETPP, as well as meso-nitrophenyloctaethylporphyrins PdOEP$\mathrm{Ph}\left(p-\mathrm{NO}_{2}\right)$ and $\mathrm{PdOEP}-\mathrm{Ph}\left(o-\mathrm{NO}_{2}\right)$ in liquid solutions at $293 \mathrm{~K}$. The aim of this study was to obtain detailed information on the effect of the conformational dynamics of the tetrapyrrole macrocycle and charge-transfer interactions on the properties of triplet states. A comprehensive analysis of the structure and dynamic properties of such objects and of their photophysical parameters is not only of interest in itself but is also required for the understanding of the role of labile conformations of metalloporphyrins in their interaction with membrane components in vivo [23], as well as for the study of artificial supramolecular systems based on tetrapyrrole macrocycles simulating a variety of biological processes [24].

\section{EXPERIMENTAL}

Structural formulas of molecules studied in this paper are presented in Fig. 1, where the corresponding abbreviations are also given. The method of synthesis of initial metal-free OEPs containing meso-substitu- 
ents of different type is described in detail in [25]. OETPP was synthesized by the method developed in [26]. The corresponding Pd complexes were synthesized from free base porphyrins of different structure by the method described in [27]. As solvents, toluene, acetone, and dimethylformamide (spectroscopic grade) were used at $293 \mathrm{~K}$ and transparent glassy methylcyclohexane-diethyl ester $(1: 1)$ and methylcyclohexanetoluene $(6: 1)$ mixtures, at $77 \mathrm{~K}$. Concentrations of porphyrin solutions were, as a rule, $\sim 10^{-6}-10^{-5} \mathrm{M}$ to decrease the influence of annihilation effects. The solutions were degassed to a residual pressure of $5 \times$ $10^{-5}$ Torr. Experiments were performed, as a rule, within 1-2 $\mathrm{h}$ after the sample preparation.

Spectral and luminescent studies and measurements on kinetic parameters of phosphorescence were performed using a high-sensitivity automated setup, which was described in detail in [28] where basic procedures, measurement errors, and the references used are also given. The decay kinetics of the excited $T_{1}$ states, the induced absorption spectra (which were measured for the first time in the near-IR region away from the $S_{0}-S_{n}$ absorption bands), as well as the singlet oxygen generation were measured with the universal measuring unit described in [29]. Samples were excited by the 532-nm second-harmonic pulses from an actively Q-switched LTI-401 Nd ${ }^{3+}$ :YAG laser (the pulse energy was $1-5 \mathrm{~mJ}$ with an accuracy of $\pm 5 \%$ and the pulse duration was $\left.\Delta t_{1 / 2}=15 \mathrm{~ns}\right)$. The detection system that included a diffraction monochromator, detectors (a FEU-84 PMT and FD-10GA germanium photodiodes), an S9-8 digital oscillograph, and a computer processing unit permitted the measurement of nonstationary absorption with an optical density as low as $\Delta D \sim 10^{-4}$ and an time resolution as low as $50 \mathrm{~ns}$ over the entire visible spectral range and in the near-IR region from 850 to $1660 \mathrm{~nm}$. The relative error of measurements of the optical density of the induced nonstationary absorption did not exceed $\pm 5 \%$.

\section{RESULTS AND DISCUSSION}

\section{Absorption and Luminescence Spectra}

In analyzing the entire spectral information obtained, it is expedient to separate the influence of a few factors that determine the spectral properties of compounds under study. Consider the role of conformational effects caused by meso-aryl substitution. One can see from Fig. 2 and the table that the transition from $\mathrm{PdOEP}$ to PdOEP-Ph at $293 \mathrm{~K}$ is accompanied by a small bathochromic shift $(\Delta \lambda \sim 4 \mathrm{~nm})$ of the long-wavelength $Q$ absorption bands, whereas the intensity and shape of the bands do not change appreciably. These molecules emit weak fluorescence at room temperature, the shape of the fluorescence bands being virtually independent of the meso-aryl substitution. A comparison of the phosphorescence spectra of PdOEP, PdTMDEP-Ph, and PdOEP-Ph at $293 \mathrm{~K}$ shows that the phenyl

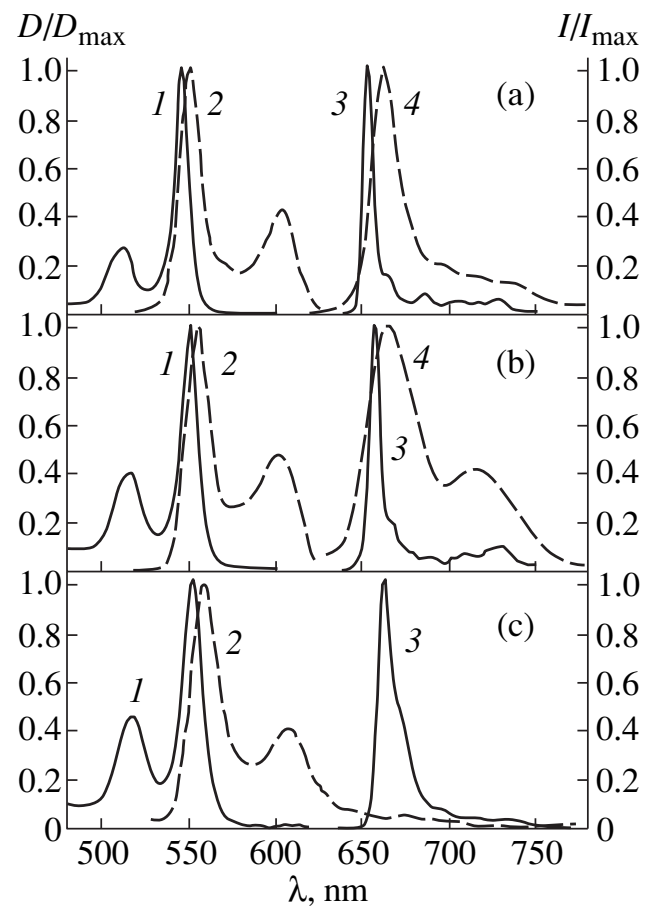

Fig. 2. (1) Absorption, (2) fluorescence, and $(3,4)$ phosphorescence spectra of (a) PdOEP, (b) PdOEP-Ph, and (c) $\mathrm{PdOEP}-\mathrm{Ph}\left(o-\mathrm{NO}_{2}\right) .(1,2,4) 293 \mathrm{~K}$; (3) $77 \mathrm{~K}$.

substitution is also manifested in a small bathochromic shift of the bands (see the table), which is accompanied by a weak increase in the relative intensity of the vibronic band (see curves 4 in Figs. $2 \mathrm{a}$ and $2 \mathrm{~b}$ ). The phosphorescence of PdOEP-Ph is strongly quenched compared to that of PdTMDEP-Ph (by a factor of 350). According to the results of our studies [13, 14], this quenching is related to the nonstationary nonplanarity of the porphyrin macrocycle in the excited $T_{1}$ state. The search for new bands in the spectral region up to $1100 \mathrm{~nm}$ at $293 \mathrm{~K}$ performed in this paper did result in the detection of the phosphorescence bands belonging to the nonplanar conformation of PdOEP-Ph molecules. We will show below that nonplanar conformations of PdOEP-Ph in the $T_{1}$ state are reliably detected in the $T-T$ absorption spectra.

One can see from Fig. 3 and the table that the transition from mono- (PdOEP-Ph) to tetra-meso-phenylsubstitution (PdOETPP) is accompanied by a strong bathochromic shift $(\Delta \lambda \sim 30-40 \mathrm{~nm})$ and broadening of the absorption and fluorescence bands at $293 \mathrm{~K}$. Under these conditions, fluorescence is weakly quenched and phosphorescence is not observed. As the temperature was decreased to $77 \mathrm{~K}$, the hypsochromic shift $(\Delta \lambda \sim 6-$ $8 \mathrm{~nm}$ ) was observed in rigid glassy matrices and the absorption and fluorescence bands were abruptly narrowed. Note that PdOETPP exhibits an intense phosphorescence band $\left(\varphi_{P}=0.25\right)$ at $705 \mathrm{~nm}$ at $77 \mathrm{~K}$ that is red-shifted relative to the phosphorescence band of usual porphyrins. Taking into account that the molecule 
Spectral and photophysical parameters of Pd porphyrins

\begin{tabular}{|c|c|c|c|c|c|c|c|c|c|c|c|c|}
\hline Compound & $\begin{array}{c}\lambda_{00}^{A}, \\
\mathrm{~nm}, \\
293 \mathrm{~K}\end{array}$ & $\begin{array}{c}\lambda_{00}^{F}, \\
\mathrm{~nm}, \\
293 \mathrm{~K}\end{array}$ & $\begin{array}{c}\lambda_{00}^{P}, \\
\mathrm{~nm}, \\
293 \mathrm{~K}\end{array}$ & $\begin{array}{c}\lambda_{00}^{P}, \mathrm{~nm} \\
77 \mathrm{~K}\end{array}$ & $\begin{array}{c}\varphi_{F} \times 10^{4}, \\
293 \mathrm{~K}\end{array}$ & $\begin{array}{l}\tau_{T}, \mu \mathrm{s}, \\
293 \mathrm{~K}\end{array}$ & $\begin{array}{l}\tau_{T}^{0}, \mu \mathrm{s}, \\
293 \mathrm{~K}\end{array}$ & $\begin{array}{c}\tau_{T}, \mathrm{~ms}, \\
77 \mathrm{~K}\end{array}$ & $\varphi_{P}^{0}, 293 \mathrm{~K}$ & $\begin{array}{c}\varphi_{P} \\
77 \mathrm{~K}\end{array}$ & $\begin{array}{l}k^{T} \times 10^{-9} \\
\mathrm{M}^{-1} \mathrm{~s}^{-1}\end{array}$ & $\gamma_{\Delta}$ \\
\hline PdOEP & 546 & 551 & 663 & 654 & 3.1 & 0.25 & 650 & 1.8 & 0.15 & 0.35 & 2.3 & $1^{*}$ \\
\hline PdOEP-Ph & 550 & 555 & 668 & 658 & 3.2 & 0.15 & 0.2 & 1.7 & 0.0006 & 0.30 & 0.9 & 0.57 \\
\hline $\mathrm{PdOEP}_{-} \mathrm{CH}_{3}$ & 555 & 559 & 668 & 670 & 3.4 & 0.27 & 350 & 1.2 & 0.08 & - & 2.1 & 1 \\
\hline PdTMDEP-Ph & 548 & 554 & 668 & 658 & 3.8 & 0.26 & 530 & 1.6 & 0.22 & 0.30 & 2.2 & 1 \\
\hline PdOETPP & 581 & 594 & - & 705 & 2 & - & $<0.05$ & 1.0 & $<10^{-5}$ & 0.25 & - & $<0.01$ \\
\hline $\operatorname{PdOEP}-\mathrm{Ph}\left(o-\mathrm{NO}_{2}\right)$ & 554 & 558 & - & 665 & 1.4 & 0.62 & 0.65 & 1.6 & $\sim 10^{-5}$ & 0.45 & 0.04 & $\sim 0.01$ \\
\hline
\end{tabular}

Note: $\lambda_{00}^{A}, \lambda_{00}^{F}$, and $\lambda_{00}^{P}$ are the maxima of the absorption (the long-wavelength transition), fluorescence, and phosphorescence bands, respectively. $\varphi_{P}$ and $\gamma_{\Delta}$ are the quantum yields of phosphorescence and singlet oxygen generation, respectively. The bimolecular rate constants $k_{T}$ of quenching of the $T_{1}$ states by molecular oxygen were calculated by the Stern-Volmer equation $\tau_{T}^{0} / \tau_{T}=1+k^{T} C \tau_{T}^{0}$, where $C=1.8 \times 10^{-3} \mathrm{M}$ is the concentration of $\mathrm{O}_{2}$ in toluene at $293 \mathrm{~K}$. The superscript " 0 " refers to degassed solutions. The PET probability for $\operatorname{PdOEP}-\mathrm{Ph}\left(o-\mathrm{NO}_{2}\right)$ was calculated by the formula $k_{\mathrm{et}}^{T}=1 / \tau_{T}^{0}$.

The error of measurement of quantum yields of emission was 5-7\% for $\varphi_{P}, \varphi_{F} \geq 0.1$; for lower values of $\varphi_{P}$ and $\varphi_{F}$, the relative error increased to $15-20 \%$. The lower limit of the measured values of $\varphi_{P}$ and $\varphi_{F}$ was $10^{-5}$. The relative errors in time decays $\tau_{T}$ and $\tau_{T}^{0}$ of the triplet states measured upon nanosecond laser excitation in the accumulation mode from the induced $T-T$ absorption at $293 \mathrm{~K}$ and in phosphorescence studied did not exceed, as a rule, $5 \%$. The relative error of measurements of the quantum yields of singlet oxygen generation was $10 \%$; the minimum measured value of $\gamma_{\Delta}$ was estimated as $\sim 0.01$.

*PdOEP was used as a reference $\left(\gamma_{\Delta}=1.0[38]\right)$.

of tetra-mesophenyl-substituted free base OETPP has a nonplanar conformation in the ground $S_{0}$ state [5], the low-temperature emission of PdOETPP should be treated as phosphorescence of the nonplanar conformation. Note that phosphorescence of nonplanar conformations of steric hindered porphyrins at $77 \mathrm{~K}$ was not reported earlier in the literature.

In the case of mono-mesophenyl-substituted $\mathrm{PdOEP}-\mathrm{Ph}$, a passage to rigid matrices at $77 \mathrm{~K}$ elimi-

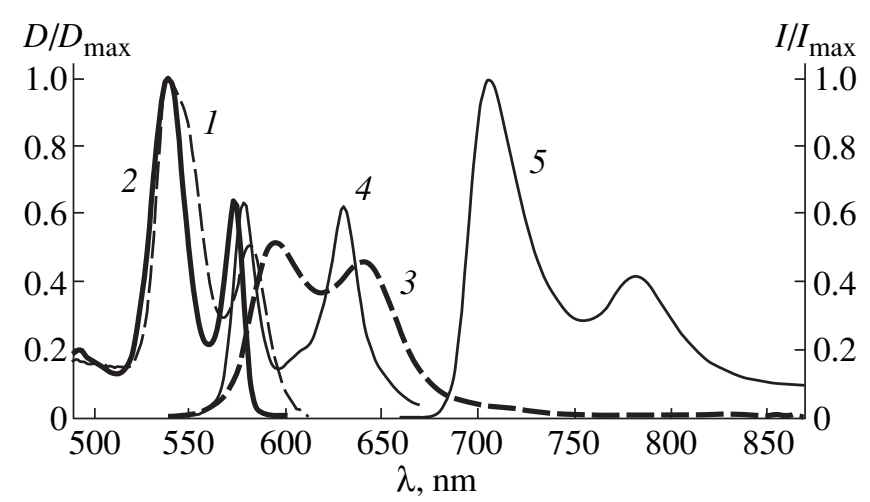

Fig. 3. $(1,2)$ Absorption, $(3,4)$ fluorescence, and (5) phosphorescence spectra of PdOETPP. $(1,3) 293 \mathrm{~K} ;(2,4,5)$ $77 \mathrm{~K}$. nates the conformation dynamics of the $\pi$-conjugated macrocycle in the $T_{1}$ state caused by the steric interaction of volume substituents $[13,14]$. As a result, the phosphorescence spectra detected under these conditions coincide with those of PdOEP and PdTMDEP-Ph (see Fig. 2 and table).

By analyzing conformational effects, note the following experimental fact that is typical for all Pd porphyrins. The phosphorescence and phosphorescence excitation spectra of these porphyrins in glassy matrices at $77 \mathrm{~K}$ (low-concentration solutions in the $6: 1$ methylcyclohexane-toluene mixture) suggest the presence of two forms having different spectra. In the case of PdOEP, the presence of these forms is manifested both in the absorption and phosphorescence spectra even at room temperature. Earlier, based on the temperature dependence of phosphorescence spectra of $\mathrm{Pd}$ porphin in nonane studied in the range from $161 \mathrm{~K}$ to $79 \mathrm{~K}$, it was assumed that it exists in two forms related to the displacement of the central Pd ion from the porphyrin macrocycle plane in the excited state [16]. Our studies of optical spectra, polarized phosphorescence, and the phosphorescence decay for different forms showed that Pd-porphyrins in solutions have two conformations already in the ground state. This issue will be discussed in detail elsewhere.

One can see from Fig. 2 and the table that the orthonitro-substitution (a passage from PdOEP-Ph to $\left.\operatorname{PdOEP}-\mathrm{Ph}\left(o-\mathrm{NO}_{2}\right)\right)$ is weakly manifested in the 
absorption and fluorescence spectra of this compound. $\operatorname{PdOEP}-\mathrm{Ph}\left(o-\mathrm{NO}_{2}\right)$ exhibit a small bathochromic shift and broadening of the purely electronic transition band by a factor of $\sim 1.5$, the Stokes shift being invariable. Similarly to the situation known for meso-tetra-(orthonitrophenyl)porphyrin [30], the spectral changes observed for $\mathrm{PdOEP}-\mathrm{Ph}\left(o-\mathrm{NO}_{2}\right)$ can be explained by admixing of the charge-transfer states to the $\pi \pi^{*}$ states of the porphyrin macrocycle.

\section{Induced Absorption Spectra}

Our earlier measurements [13, 14, 20 22] showed that free bases of steric hindered mono- and dimesophenyl-substituted OEP molecules do not emit noticeable phosphorescence in liquid solutions at $293 \mathrm{~K}\left(\varphi_{P}<\right.$ $10^{-5}$ ). This is also the case for most free bases of usual porphyrins in liquid solutions at room temperature. In this case, the analysis of induced absorption spectra can give information on the spectral properties of triplet states of steric hindered porphyrins in the presence of conformation dynamics.

One can see from Fig. 4 that the intensity of the $T-T$ absorption spectrum of the OEP molecule monotonically decreases in the near-IR region up to $1660 \mathrm{~nm}$. In passing to the steric hindered OEP-Ph molecule, the $T-T$ absorption spectra in this region exhibit two distinct maxima at 740 and $1000 \mathrm{~nm}$, the half-width of the long-wavelength band being considerably greater. The $T-T$ absorption spectrum of the $\mathrm{OEP}-\mathrm{Ph}\left(O-\mathrm{CH}_{3}\right)$ molecule does not exhibit a band at $1000 \mathrm{~nm}$, whereas its short-wavelength band is less pronounced and is shifted to the blue $(720 \mathrm{~nm})$ compared to the corresponding band in the OEP-Ph spectrum. These spectra can be interpreted as follows.

We showed recently [12-14] that the introduction of volume substituents into the ortho position of the phenyl ring of $\beta$-alkyl-substituted porphyrins (a passage from $\mathrm{OEP}-\mathrm{Ph}$ to $\mathrm{OEP}-\mathrm{Ph}\left(o-\mathrm{CH}_{3}\right)$ ) substantially increases steric interactions and hinders torsion vibrations of mesophenyl around a singular $\mathrm{C}-\mathrm{C}$ bond. In this case, unlike OEP-Ph, the OEP-Ph $\left(o-\mathrm{CH}_{3}\right)$ molecule remains planar in the excited $T_{1}$ state and has a long lifetime $\tau_{T}^{0}$ in degassed solutions at $293 \mathrm{~K}$. Taking into account these facts, the presence of the long-wavelength band at $1000 \mathrm{~nm}$ in the $T-T$ absorption spectrum of the OEP-Ph molecule should be related to the dynamic nonplanarity of the porphyrin macrocycle. Because, at present, a rigorous theoretical model that would describe the $T-T$ absorption spectra of porphyrins is absent, we can only qualitatively explain the spectral features observed. According to [26], nonplanar porphyrins in the initial $S_{0}$ state are characterized by the destabilization of the $\pi$-conjugated system of the macrocycle, which results in a substantial increase in the energy of the highest-energy occupied molecular orbitals (HOMOs) and a small change in the energy of

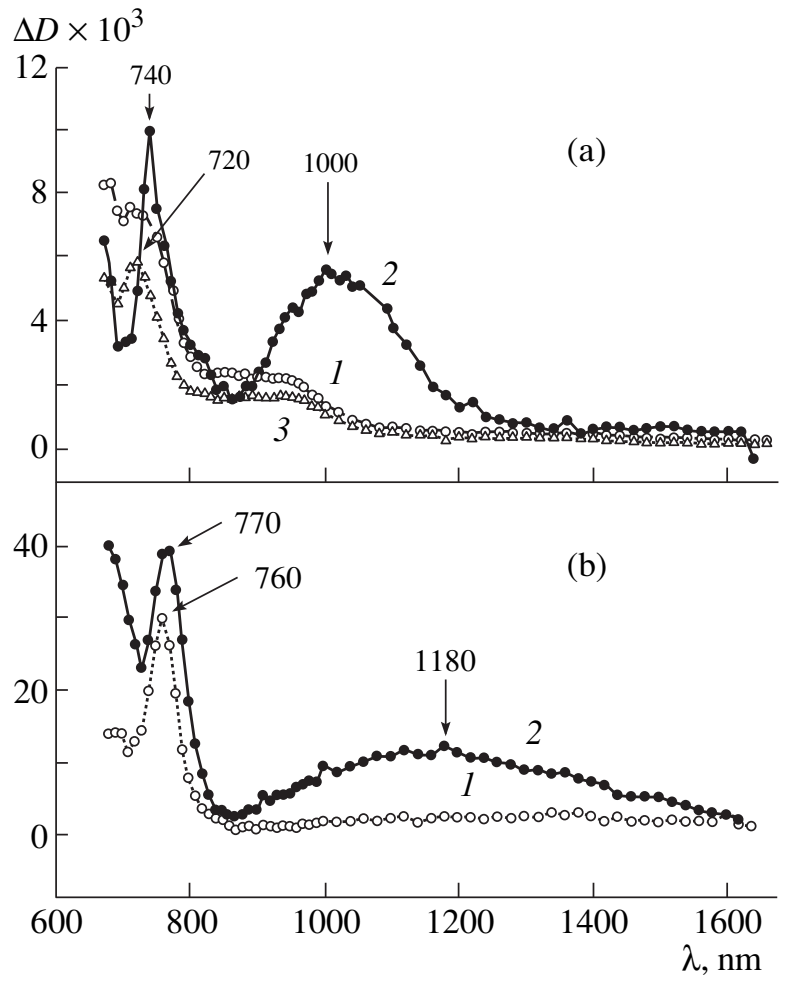

Fig. 4. Induced $T-T$ absorption spectra of (a) free bases and (b) Pd complexes of octaethylporphyrins and their mesophenyl-substituted derivatives in degassed toluene at $293 \mathrm{~K}$. (a) (1) OEP, (2) OEP-Ph, (3) OEP-Ph $\left(o-\mathrm{CH}_{3}\right)$; (b) (1) PdOEP, (2) PdOEP-Ph.

the lowest-energy unoccupied molecular orbitals (LOMOs). As a result, a decrease in the energy gap between the LOMO and HOMO is accompanied by the red shift of the absorption bands. Because steric interactions in the OEP-Ph molecule lead to the dynamical distortion of the tetrapyrrole macrocycle only in the triplet state, the presence of the long-wavelength band at $1000 \mathrm{~nm}$ in the $T-T$ absorption spectrum can be attributed to a change in the HOMO energy in the nonplanar conformation. In addition, the distortion of the porphyrin macrocycle can result in the additional mixing of triplet states of different types ( $\pi \pi^{*}$ and $n \pi^{*}$ transitions) caused by the displacement of nitrogen atoms from the macrocycle plane $[13,14]$ and by the corresponding increase in the contributions from one-center overlap integrals for $n$ orbitals of nitrogen and $\pi$ orbitals of the macrocycle [31]. Because the dynamic distortion of the porphyrin macrocycle of the OEP-Ph $(o-$ $\mathrm{CH}_{3}$ ) molecule in the triplet state is eliminated, the long-wavelength band at $1000 \mathrm{~nm}$ is absent.

The presence of the 740-nm band in the $T-T$ absorption spectrum of OEP-Ph and its absence in the induced absorption spectrum of the OEP molecule can be attributed to a change in the nature of the lowest triplet state upon meso-aryl substitution. The lowest $T_{1}$ level of the $\mathrm{OEP}-\mathrm{Ph}$ molecule, as an analogous level of the tet- 


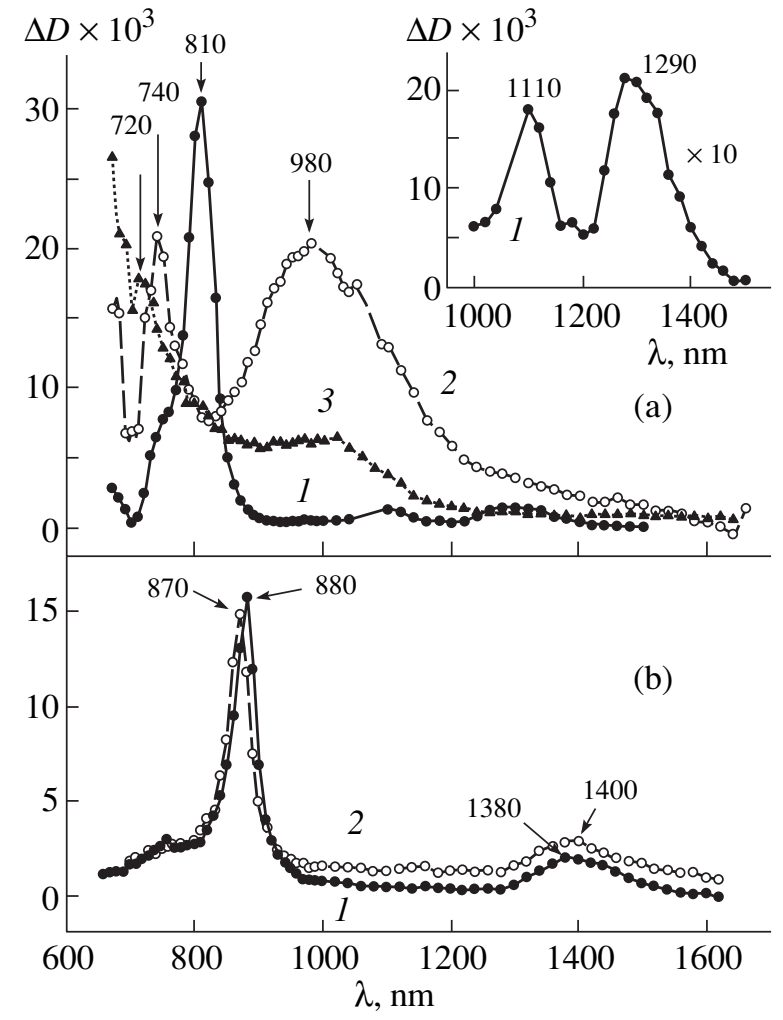

Fig. 5. Induced absorption spectra of (a) free bases and (b) Pd complexes of meso-nitrophenyl-substituted octaethylporphyrins in degassed solutions at $293 \mathrm{~K}$. (a) (l) OEP$\mathrm{Ph}\left(o-\mathrm{NO}_{2}\right)$ in toluene, (2) OEP-Ph $\left(p-\mathrm{NO}_{2}\right)$ in toluene, (3) $\mathrm{OEP}-\mathrm{Ph}\left(p-\mathrm{NO}_{2}\right)$ in acetone; (b) (1) $\operatorname{PdOEP}-\mathrm{Ph}\left(o-\mathrm{NO}_{2}\right)$ in toluene, (2) $\mathrm{PdOEP}-\mathrm{Ph}\left(o-\mathrm{NO}_{2}\right)$ in acetone.

raphenylporphyrin (TPP) related to the 740-nm band in the $T-T$ absorption spectrum [32] corresponds to the ${ }^{3}\left(3 a_{2 u} 4 e_{g}\right)$ configuration, whereas the lowest level of the OEP molecule is the $T_{1}$ level with the ${ }^{3}\left(1 a_{1 u} 4 e_{g}\right)$ configuration. In passing to the OEP-Ph $\left(o-\mathrm{CH}_{3}\right)$ molecule, the band under consideration becomes weaker and experiences the hypsochromic shift to $720 \mathrm{~nm}$. These can be explained by the fact that, unlike OEP-Ph, the influence of mesophenyl in the $\operatorname{OEP}-\mathrm{Ph}\left(o-\mathrm{CH}_{3}\right)$ molecule is minimal because the phenyl ring is virtually perpendicular to the porphyrin macrocycle plane due to steric interactions [20,22].

The nonplanarity effects are also observed in the $T-T$ absorption spectra of the Pd complexes of molecules under study (Fig. 4b). The short-wavelength at 760$770 \mathrm{~nm}$ observed in the spectra of both PdOEP and PdOEP-Ph can be attributed, in our opinion, to nonplanar deformations of the tetrapyrrole macrocycle caused by the displacement of the central Pd ion from the porphyrin ligand plane. In this case, due to a large ion radius of $\mathrm{Pd}^{2+}(0.86 \AA$ [33]), the Pd complexes of OEP have the dome conformation in the ground state, whose symmetry is lower that the initial symmetry $D_{4 h}$. The out-of-plane vibrations of a metal in this conformation are strongly anharmonic [34]. Note that such a band was observed at $\sim 760 \mathrm{~nm}$ in the $T-T$ absorption spectrum of PdTPP in pyridine [35]. However, the origin of this band was not discussed, although the formation of mono-pyridinate complexes should result in the distortion of the planarity of the porphyrin macrocycle due to the displacement of the Pd ion from the macrocycle plane.

The $T-T$ absorption spectrum of PdOEP-Ph exhibits a broad structureless band at $1180 \mathrm{~nm}$ (Fig. 4b). This band and its large width can be caused by a combination of at least two effects: the dynamic distortion of the tetrapyrrole macrocycle in the triplet state (as in the case of OEP-Ph) and a change in the nature of the lowest triplet state upon meso-aryl substitution (the presence of the 845-nm band in the $T-T$ absorption spectrum of PdTPP and ZnTPP [35]).

Consider the influence of the meso-nitrophenyl substitution on the induced absorption spectra of molecules under study upon variation of the position of the $\mathrm{NO}_{2}$ group in the phenyl ring (ortho- and para-substitution). One can see from Fig. 5a that the induced absorption spectrum of OEP-Ph $\left(p-\mathrm{NO}_{2}\right)$ contains a longwavelength band at $1000 \mathrm{~nm}$ and in fact coincides with the $T-T$ absorption spectrum of OEP-Ph (Fig. 4a). This result is explained by the fact that the introduction of the bulk substitute into the para-position does not affect torsion librations of the phenyl ring and, thus, does not eliminate the dynamic nonplanarity of the porphyrin macrocycle in the $T_{1}$ state [12-14]. In addition, in the presence of the electron-acceptor group in the paraposition that is the farthest removed from porphyrin the charge-transfer interactions is inefficient [20-22], so that their influence on the induced absorption spectra is negligible. Thus, the induced absorption spectrum of OEP-Ph $\left(p-\mathrm{NO}_{2}\right)$ is in fact the $T-T$ absorption spectrum. The decrease in the intensity of the 1000-nm band of $\mathrm{OEP}-\mathrm{Ph}\left(p-\mathrm{NO}_{2}\right)$ in acetone (Fig. 5a) can be explained by the enhancement of charge-transfer interactions in polar media resulting in the shortening of the tripletstate lifetime [20] and, hence, in a decrease in the efficiency of formation of nonplanar conformations related to this band.

The induced absorption spectrum of $\mathrm{OEP}-\mathrm{Ph}(o-$ $\mathrm{NO}_{2}$ ) (Fig. 5a) substantially differs from the two spectra considered above. Note that the 1000-nm band related to nonplanar conformations in the $T_{1}$ state completely disappears. Along with the residual absorption at $740 \mathrm{~nm}$ (caused by the mesophenyl substitution), an intense narrow band appears at $810 \mathrm{~nm}$ and two lowintensity bands appear at 1110 and $1290 \mathrm{~nm}$. We found earlier [20] that the energy of the charge-transfer (CT) state for OEP-Ph $\left(o-\mathrm{NO}_{2}\right)$ in toluene exceeds the energy of the locally excited $T_{1}$ state by $0.24 \mathrm{eV}$. Therefore, from energy considerations, the new bands observed cannot be assigned to the $T_{1} \longrightarrow$ CT absorption transitions. A manifestation of the intrinsic absorption in a system of the states of the ion-radical pair is also 
unlikely because of a fast transition from the ${ }^{3}\left[\mathrm{P}^{+} \ldots \mathrm{NO}_{2}^{-}\right]$CT state to the lower-lying $T_{1}$ state $\left(E_{\mathrm{CT}}>\right.$ $\left.E_{T 1}[20]\right)$. One can assume that the induced absorption spectrum of OEP-Ph $\left(o-\mathrm{NO}_{2}\right)$ is caused by the mixing of pure $\pi \pi^{*}$ states with the CT states due to the overlap of the orbitals of the porphyrin macrocycle and nitro group. Assumptions of this type were used for the explanation of the transformation of absorption spectra of porphyrin-quinone complexes [30].

One can see from Fig. $5 b$ that the induced absorption spectra of PdOEP-Ph $\left(o-\mathrm{NO}_{2}\right)$ are similar to the analogous spectrum of OEP- $\mathrm{Ph}\left(o-\mathrm{NO}_{2}\right)$, except as regards the bathochromic shift of the bands. The lowintensity at $760-770 \mathrm{~nm}$ in the spectrum of PdOEP$\mathrm{Ph}\left(o-\mathrm{NO}_{2}\right)$ observed both for PdOEP and PdOEP-Ph is caused by the displacement of the central Pd ion from the porphyrin ligand plane and is not related to the presence of the nitro group. The bathochromic shift of the bands can be explained by several causes : a change in the symmetry of the OEP-Ph $\left(o-\mathrm{NO}_{2}\right)$ molecule caused by the introduction of the $\mathrm{Pd}$ ion (which also results in the transformation of two long-wavelength bands in a region of 1100-1400 to one band), thermal mixing of the transitions in a system of locally excited triplet levels and the CT states in an ion-radical pair, and an inversion of the energies of the $T_{1}$ and CT states in passing to the Pd complex $\left(\Delta E=E_{T 1}-E_{\mathrm{CT}} \approx 2 k T\right.$ in toluene; this question is considered below in detail in analysis of the PET properties). Note finally that the induced absorption spectrum of $\mathrm{PdOEP}-\mathrm{Ph}\left(o-\mathrm{NO}_{2}\right)$ virtually does not change in passing to highly polar media (Fig. 5b). This can be caused by a weak dependence of the CT state energy in this system on the medium polarity due to the screening effect and specific solvation (see below analysis of the PET properties).

\section{Deactivation of Excited States}

Analysis of the experimental data presented in the table revealed the following features. The mesophenyl substitution in PdOEP-Ph, as for free bases of OEP molecules [12-14], does not affect the quantum yield of fluorescence $\varphi_{F}$ in degassed solutions at $293 \mathrm{~K}$; however, it results in a drastic decrease in the quantum yield of phosphorescence $\varphi_{P}^{0}$ and an abrupt shortening of the triplet-state lifetime $\tau_{T}^{0}$ from $650 \mu$ s to $200 \mathrm{~ns}$. At the same time, such effects was not observed upon mesoalkyl substitution (PdOEP- $\left.\mathrm{CH}_{3}\right)$ and in the absence of bulk substituents in the $\beta$-positions of pyrrole rings adjacent to meso-phenyl (PdTMDEP-Ph). A small shortening of $\tau_{T}^{0}$ for PdOEP-CH${ }_{3}$ and PdTMDEP-Ph compared to PdOEP was attributed to a decrease in the symmetry of the molecules and a decrease in the energy of the $T_{1}$ level upon mono-meso-substitution, resulting in the increase in the probability of intersystem crossing [36]. The quenching of the $T_{1}$ state of PdOEP-Ph is completely absent in frozen solutions at $77 \mathrm{~K}$. In this case, the values of $\varphi_{P}^{0}$ and $\tau_{T}^{0}$ virtually coincide with those for PdOEP.

Our data on quenching of the $T_{1}$ states of the molecules under study by molecular oxygen showed that the mono-mesosubstitution does not affect the quenching rate constant $\left(k^{T} \approx 2 \times 10^{9} \mathrm{M}^{-1} \mathrm{~s}^{-1}\right)$ for $\mathrm{PdOEP}-\mathrm{CH}_{3}$ and PdTMDEP-Ph, which is typical for usual metalloporphyrins [37]. The rate constant of quenching of the $T_{1}$ state for PdOEP-Ph in toluene decreases to $k^{T}=9 \times$ $10^{8} \mathrm{M}^{-1} \mathrm{~s}^{-1}$ and the efficiency of singlet oxygen generation decreases correspondingly.

The properties of triplet states of PdOEP-Ph observed in liquid solutions at $293 \mathrm{~K}$ reflect all the features of the deactivation of the $T_{1}$ states of free bases of mono- and di-mesophenyl-substituted steric hindered octaetylporphyrins studied earlier by us [12-14]. Note that, as the number of meso-phenyls was increased (i.e., in passing to PdOETPP), the quantum yield of phosphorescence of PdOEP-Ph in toluene at $293 \mathrm{~K}$ further decreased $\left(\varphi_{P}^{0}<10^{-5}\right)$, the lifetime of the $T_{1}$ state shortened $\left(\tau_{T}^{0}<50 \mathrm{~ns}\right)$, and the efficiency of the singlet oxygen generation drastically decreased $\left(\gamma_{\Delta}<0.01\right)$. According to [5], tetra-mesophenyl-substituted octaethylporhyrins have the nonplanar $\pi$-conjugated macrocycle in the ground $S_{0}$ state, which results in a considerable increase in the probability of nonradiative $S_{1} \leadsto T_{1}$ and $S_{1} \leadsto S_{0}$ transitions. Our data showed that the probability of the nonradiative $T_{1} \leadsto S_{0}$ decay of the $T_{1}$ state in such steric hindered porphyrins also substantially increases. One can see from the table that the quantum yield of fluorescence of the PdOETPP molecule virtually coincides with the values of $\varphi_{F}$ measured for other Pd complexes. This means that the nonradiative decay of the $S_{1}$ state in PdOETPP is mainly determined by the internal heavy atom effect and the exchange $d-\pi^{*}$ interactions [18], whereas the dynamic distortion of the porphyrin macrocycle is inefficient.

As was mentioned above, the introduction of bulk substituents $\left(\mathrm{CH}_{3}, \mathrm{OCH}_{3}, \mathrm{~F}\right)$ into the ortho position of phenyl in molecules of the type OEP-Ph prevents the dynamic nonplanarity of the porphyrin macrocycle in the $T_{1}$ state in liquid phase at $293 \mathrm{~K}$ and is accompanied by a considerable lengthening of the lifetime $\tau_{T}^{0}$. At the same time, the value of $\tau_{T}^{0}$ does not increase after the introduction of the bulk $\mathrm{NO}_{2}$ group into the ortho position of the phenyl ring (in passing from OEP-PH to OEP-Ph $\left(o-\mathrm{NO}_{2}\right)$ ) but even shortens, which is caused, as was shown earlier by us $[13,20]$, by mixing of the locally excited $T_{1}$ state of porphyrin with the higherlying CT state of the ion-radical pair and the thermally activated $T_{1} \leadsto$ CT transition. 
One can see from the table that the quantum yield of phosphorescence of $\mathrm{PdOEP}-\mathrm{Ph}\left(o-\mathrm{NO}_{2}\right)$ decreases to $\varphi_{P}^{0} \sim 10^{-5}$ and the lifetime of the induced absorption of this molecule shortens to $\tau_{T}^{0}=650 \mathrm{~ns}$. The decrease in the rate of quenching of the excited $T_{1}$ states of PdOEP$\mathrm{Ph}\left(o-\mathrm{NO}_{2}\right)$ by molecular oxygen $\left(k^{T} \approx 4 \times 10^{7} \mathrm{M}^{-1} \mathrm{~s}^{-1}\right)$ can be caused by a decrease in the contribution of the CT states of oxygen in the collision complex [ ${ }^{3} \mathrm{PdOEP}-$ $\left.\mathrm{Ph}\left(o-\mathrm{NO}_{2}\right) \ldots{ }^{3} \mathrm{O}_{2}\right]$ due to the presence of the electronacceptor nitro group bonded with the macrocycle [38]. In addition, a drastic decrease in the efficiency of the singlet oxygen generation $\left(\gamma_{\Delta} \sim 0.01\right)$ along with relatively long lifetimes of the induced absorption $\left(\tau_{T}^{0}=\right.$ $650 \mathrm{~ns}$ ) suggests that the detected absorption is mainly related to the ion-radical pair found in the thermodynamical equilibrium with the $T_{1}$ state.

Note, however, that the quenching mechanism of the $T_{1}$ state in the PdOEP-Ph $\left(o-\mathrm{NO}_{2}\right)$ molecule substantially differs from that for its metal-free analog OEP$\mathrm{Ph}\left(o-\mathrm{NO}_{2}\right)$, which is explained by different mutual arrangement of the locally excited $T_{1}$ level of the porphyrin macrocycle and the CT state in these molecules. The energy of the CT state for PdOEP-Ph $\left(o-\mathrm{NO}_{2}\right)$ in a condensed phase can be estimated from the known expression [39]

$$
E_{\mathrm{CT}}=e\left(E_{1 / 2}^{\mathrm{ox}}-E_{1 / 2}^{\mathrm{red}}\right)-W,
$$

where $E_{1 / 2}^{\mathrm{ox}}=0.82 \mathrm{~V}$ [40] is the one-electron oxidation potential of the donor PdOEP and $E_{1 / 2}^{\mathrm{red}}=-1.08 \mathrm{~V}$ [41] is the reduction potential of the electron acceptor (nitrobenzene) determined with respect to a calomel electrode in dimethylformamide (DMF, $\varepsilon=36.7$ ). The Coulomb stabilization energy $W=e^{2} / 4 \pi \varepsilon_{0} \varepsilon r_{\mathrm{DA}}$ in DMF for the distance $r_{\mathrm{DA}}=5.7 \AA$ between the centers of porphyrin and the $\mathrm{NO}_{2}$ group for the optimized OEP-Ph $(o-$ $\mathrm{NO}_{2}$ ) structure [20] is $0.07 \mathrm{eV}$. Because the reactant radii $r_{\mathrm{D}}=5 \AA$ and $r_{\mathrm{A}}=3.5 \AA$ [20] for OEP-Ph $\left(o-\mathrm{NO}_{2}\right)$ and $\operatorname{PdOEP}-\mathrm{Ph}\left(o-\mathrm{NO}_{2}\right)$ are comparable to the intercenter distance $r_{\mathrm{DA}}$ and the condition $\mathrm{r} r_{\mathrm{DA}}>r_{\mathrm{D}}+r_{\mathrm{A}}$ [42] is not fulfilled, the above value of $W$ is only an approximate estimate. The experimental value of the CT state energy can be determined from the value of the energy gap $\Delta E=E_{\mathrm{CT}}-E_{T}$ obtained for OEP-Ph $(o-$ $\mathrm{NO}_{2}$ ) in [20] from the Boltzmann temperature dependence of the quenching rate of the $T_{1}$ state in solvents of different polarity. The values of the CT state energy for OEP-Ph $\left(o-\mathrm{NO}_{2}\right)$ obtained in this way were $1.75 \mathrm{eV}$ in acetone and $1.78 \mathrm{eV}$ in toluene. Taking into account the closeness of the oxidation potentials of OEP (0.81 V [40]) and PdOEP (0.82 V [40]) and the closeness of the optimized structures of OEP-Ph $\left(o-\mathrm{NO}_{2}\right)$ and $\operatorname{PdOEP}-\mathrm{Ph}\left(o-\mathrm{NO}_{2}\right)$, we can assume that the experimental values of the CT state energy for $\operatorname{PdOEP}-\mathrm{Ph}\left(o-\mathrm{NO}_{2}\right)$ in DMF is $1.76 \mathrm{eV}$ and $1.79 \mathrm{eV}$ in toluene. Thus, we will use the experimental values of the CT state in solutions of different polarity in our quantitative analysis of the CT interactions in PdOEP-Ph $\left(o-\mathrm{NO}_{2}\right)$.

The measurements of phosphorescence of PdOEP$\mathrm{Ph}\left(o-\mathrm{NO}_{2}\right)$ at $77 \mathrm{~K}$, taking into account the bathochromic shift of the phosphorescence bands with increasing temperature to $293 \mathrm{~K}$ (see Fig. 2 and the table), gave the $T_{1}$ state energy of this molecule in DMF at room temperature equal to $1.84 \mathrm{eV}$. Therefore, unlike the OEP$\mathrm{Ph}\left(o-\mathrm{NO}_{2}\right)$ molecule, where the $T_{1}$ state energy $\left(E_{T}=\right.$ $1.56 \mathrm{eV}$ in DMF) is lower than the CT state energy, for the $\mathrm{PdOEP}-\mathrm{Ph}\left(o-\mathrm{NO}_{2}\right)$ molecule, $E_{T}>E_{\mathrm{CT}}$ both in polar and nonpolar solvents at $293 \mathrm{~K}$. This means that the quenching of the $T_{1}$ state of $\operatorname{PdOEP}-\mathrm{Ph}\left(o-\mathrm{NO}_{2}\right)$ is caused by the photoinduced electron transfer to the lower-lying CT state of the ion-radical pair ${ }^{3}$ [porphy$\operatorname{rin}^{+} \ldots \mathrm{NO}_{2}^{-}$].

It follows from the data presented in the table that the rate constant of PET involving the triplet states of $\operatorname{PdOEP}-\mathrm{Ph}\left(o-\mathrm{NO}_{2}\right)$ is $k_{\mathrm{et}}^{T}=1.5 \times 10^{6} \mathrm{~s}^{-1}$ in toluene at $293 \mathrm{~K}$, and it increases to $k_{\mathrm{et}}^{T}=4.0 \times 10^{6} \mathrm{~s}^{-1}$ in DMF. Such a tendency is typical for the exothermic nonadiabatic PET [39]. In this case, the quantum yield of formation of the ion-radical pair ${ }^{3}\left[\right.$ porphyrin $\left.{ }^{+} \ldots \mathrm{NO}_{2}^{-}\right]$for $\mathrm{PdOEP}-\mathrm{Ph}\left(o-\mathrm{NO}_{2}\right)$ in the solutions used is

$$
\varphi_{\mathrm{et}}^{T}=\frac{k_{\mathrm{et}}^{T}}{\left(p+q+k_{\mathrm{et}}^{T}\right)}=0.99,
$$

where $p+q=1.5 \times 10^{3} \mathrm{~s}^{-1}$ is the total probability of the $T_{1} \longrightarrow S_{0}$ phosphorescence and the nonradiative $T_{1} \leadsto S_{0}$ decay of the PdOEP molecule at $293 \mathrm{~K}$. Note that, for the porphyrin-quinone pair at $r_{\mathrm{DA}}=14 \AA$ in polar media, $k_{\mathrm{et}}^{T} \sim 10^{4}-10^{5} \mathrm{~s}^{-1}$ [43].

Within the framework of the semiclassical Marcus theory [39, 42], the probability $k_{\text {et }}^{T}$ of the nonadiabatic PET in the "normal" region has the form

$$
k_{\mathrm{et}}^{T}=\frac{2 \pi}{\hbar} \frac{V^{2}}{\left(4 \pi \lambda k_{\mathrm{B}} T\right)^{1 / 2}} \exp \left(-\frac{\Delta G^{*}}{k_{\mathrm{B}} T}\right),
$$

where $k_{\mathrm{B}}$ is the Boltzmann constant; $V$ is the matrix element of the electronic interaction in the DA pair; $\lambda=$ $\lambda_{\text {in }}+\lambda_{\text {solv }}$ is the reorganization energy; and $\Delta G^{*}$ is the value of the activation PET barrier. The reorganization energy of a solvate is calculated from the expression

$$
\lambda_{\text {solv }}=\frac{e^{2}}{4 \pi \varepsilon}\left[\frac{1}{2 r_{\mathrm{D}}}+\frac{1}{2 r_{\mathrm{A}}}-\frac{1}{r_{\mathrm{DA}}}\right]\left[\frac{1}{\varepsilon_{\mathrm{op}}}-\frac{1}{\varepsilon}\right]
$$

where $\varepsilon_{\mathrm{op}}=n^{2}$ and $\varepsilon$ are optical and static dielectric constants of a solvent, respectively $(n=1.49693$ and $\varepsilon=$ 

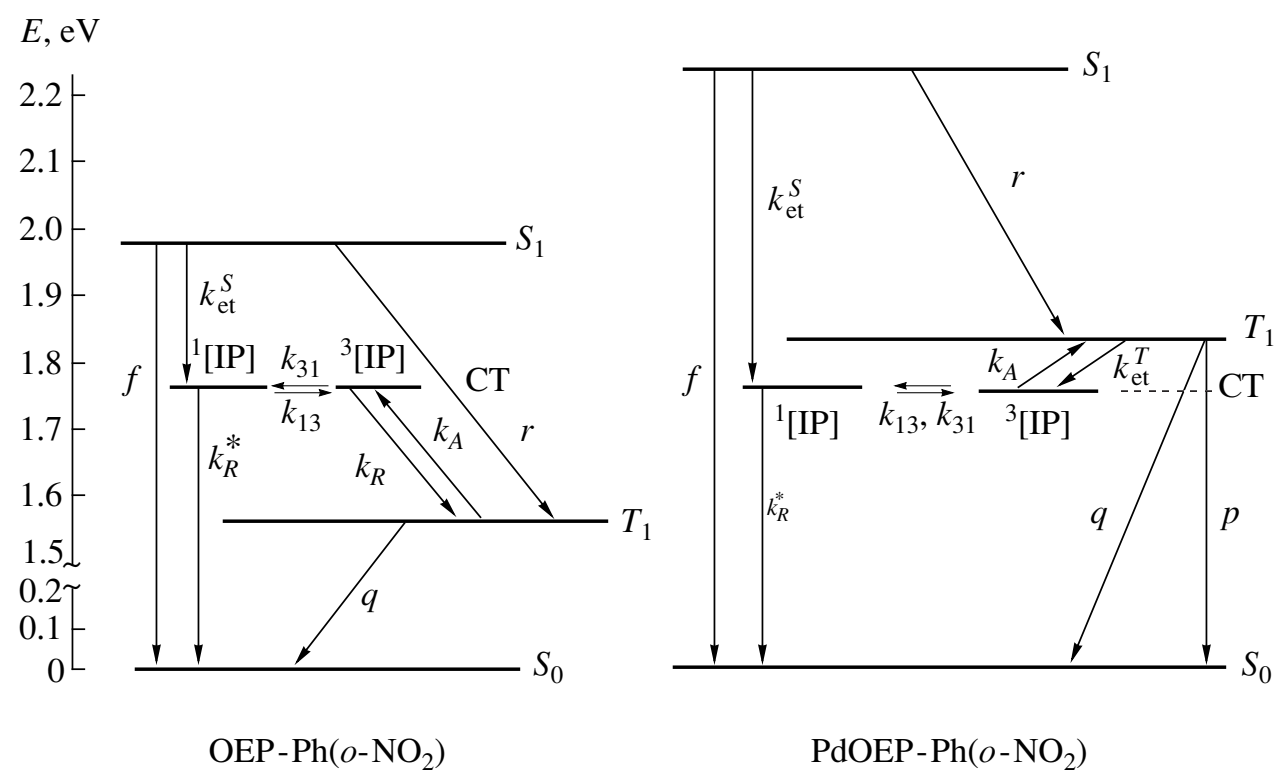

Fig. 6. Energy level diagrams and decay channels of locally excited $S_{1}$ and $T_{1}$ states of the porphyrin macrocycle and the CT states in the ion-radical pair for OEP-Ph $\left(o-\mathrm{NO}_{2}\right)$ and $\mathrm{PdOEP}-\mathrm{Ph}\left(o-\mathrm{NO}_{2}\right)$ molecules in polar solvents at $293 \mathrm{~K}$. $f, r, p$, and $q$ are the probabilities of the $S_{1} \longrightarrow S_{0}$ fluorescence, the $S_{1} \leadsto T_{1}$ intersystem crossing, the $T_{1} \longrightarrow S_{0}$ phosphorescence, and the $T_{1} \sim S_{0}$ nonradiative decay, respectively; $k_{\mathrm{et}}^{S}$ and $k_{\mathrm{et}}^{T}$ are the rate constant of PET involving the excited $S_{1}$ and $T_{1}$ states, respectively; $k_{\mathrm{A}}$ is the probability of thermally activated population of the higher-lying states; $k_{31}$ and $k_{13}$ are the probabilities of spin dephasing of the ion-radical pair; $k_{R}^{*}$ and $k_{R}$ are the probabilities of recombination of the singlet and triplet ion-radical pair, respectively; and ${ }^{1}$ [IP] and ${ }^{3}[\mathrm{IP}]$ are the singlet and triplet states of the ion-radical pair.

2.38 for toluene; and $n=1.43047$ and $\varepsilon=36.7$ for DMF [41]). Therefore, the reorganization energy of the solvent is, according to our estimates, $\lambda_{\text {solv }}=0.03 \mathrm{eV}$ for toluene and $0.45 \mathrm{eV}$ for DMF. The internal reorganization energy $\lambda_{\text {in }}$, which is determined by a change in the geometrical parameters of the equilibrium conformations of the DA pair, is estimated as $\sim 0.2 \mathrm{eV}$ for porphyrin macrocycles [43]. Therefore, the total reorganization energy for $\operatorname{PdOEP}-\mathrm{Ph}\left(o-\mathrm{NO}_{2}\right)$ in toluene and DMF is $\lambda=0.23$ and $0.65 \mathrm{eV}$, respectively. The free Gibbs energy $\Delta G^{0}$ of $\operatorname{PdOEP}-\mathrm{Ph}\left(o-\mathrm{NO}_{2}\right)$ calculated from the expression

$$
\Delta G^{0}=e\left(E_{1 / 2}^{\mathrm{ox}}-E_{1 / 2}^{\mathrm{red}}\right)-W-E_{T}
$$

is $-0.05 \mathrm{eV}$ in toluene and $-0.08 \mathrm{eV}$ in DMF.

The PET activation energies $\Delta G^{*}$ determined from the expression

$$
\Delta G^{*}=\frac{\left(\Delta G^{0}+\lambda\right)^{2}}{4 \lambda}
$$

are estimated as $0.035 \mathrm{eV}$ in toluene and $0.125 \mathrm{eV}$ in DMF. Because, in both solvents, $\left|-\Delta G^{0}\right|<\lambda$, PET in $\operatorname{PdOEP}-\mathrm{Ph}\left(o-\mathrm{NO}_{2}\right)$ involving the triplet state corresponds to the "normal" region in the Marcus parabolic dependence, $\log k_{\text {et }}=f\left(-\Delta G^{0}\right)$.
Using the PET parameters estimated in this way, experimental values of the rate constants $k_{\mathrm{et}}$, and expression (3), we calculated the matrix elements of the electronic interaction for the PdOEP-Ph $\left(o-\mathrm{NO}_{2}\right)$ molecule in polar and nonpolar media $V=0.05 \mathrm{~cm}^{-1}$ in toluene and $V=1.2 \mathrm{~cm}^{-1}$ in DMF. An increase in $V$ in passing from weakly polar solvents to polar solvents has also been observed for the porphyrin-quinine complex and has been explained by a change in the geometry and intercenter distances in a hydrophobic D-A pair in the polar environment [44]. It is possible that, in the case of PdOEP-Ph $\left(o-\mathrm{NO}_{2}\right)$, the equilibrium conformation of the D-A pair changes upon variation of the polarity of the solvate environment. This results in the change in the overlap of molecular orbitals of the $\pi$ conjugated macrocycle and the $\mathrm{NO}_{2}$ group, which determines the value of $V$ in PET according to the through-space mechanism [39, 42]. The values of $V=$ $0.05-1.2 \mathrm{~cm}^{-1}$ obtained by us for different solvents satisfy the known Landau-Zener criterion for nonadiabatic PET reactions [45]

$$
4 \pi^{2} V^{2} / h \omega\left(2 \lambda k_{\mathrm{B}} T\right)^{1 / 2}<1,
$$

where $\omega \approx 100 \mathrm{~cm}^{-1}$ at $300 \mathrm{~K}$ are averaged frequencies of the molecular vibrations of reagents and of the orientation motion of the solvent. Therefore, quenching of the triplet state of PdOEP-Ph $\left(o-\mathrm{NO}_{2}\right)$ both in polar and 
nonpolar solvents at room temperature corresponds to the nonadiabatic PET.

Thus, using the PET parameters and the data on the decay of the excited states of PdOEP-Ph $\left(o-\mathrm{NO}_{2}\right)$, we can suggest the following scheme of relaxation processes taking place upon photoexcitation of this molecule (Fig. 6):

$$
\begin{gathered}
\left(S_{1}\right)\left[{ }^{1} \mathrm{P} \ldots \mathrm{NO}_{2}\right] \stackrel{r}{\longrightarrow}\left(T_{1}\right)\left[{ }^{3} \mathrm{P} \ldots \mathrm{NO}_{2}\right] \\
\stackrel{k_{k_{\mathrm{A}}}^{T}}{\longrightarrow}\left[\mathrm{P}^{+} \ldots \mathrm{NO}_{2}^{-}\right] \underset{k_{13}}{\stackrel{k_{31}}{\longrightarrow}}\left[\mathrm{P}^{+} \ldots \mathrm{NO}_{2}^{-}\right] \stackrel{k_{R}^{*}}{\longrightarrow}\left[\mathrm{P} \ldots \mathrm{NO}_{2}\right]\left(S_{0}\right),
\end{gathered}
$$

where $r$ is the probability of the $S_{1} \leadsto T_{1}$ intersystem crossing, $k_{\mathrm{et}}^{T}$ is the PET probability, $k_{\mathrm{A}}$ is the probability of the thermally activated population of the $T_{1}$ state of porphyrin from the lower-lying CT state of the ion-radical pair, $k_{31}$ and $k_{13}$ are the probabilities of the spin dephasing of the ion-radical pair, and $k_{R}^{*}$ is the probability of recombination of the singlet ion-radical pair to the ground state. It follows from the energy level diagram that, in principle, the direct PET from the $S_{1}$ state of $\mathrm{PdOEP}-\mathrm{Ph}\left(o-\mathrm{NO}_{2}\right)$ is also possible. Our calculations showed that, in this case, the free Gibbs energy in toluene $\Delta G^{0}=-0.43 \mathrm{eV}$. Therefore, $\left|-\Delta G_{0}\right|>\lambda=0.23 \mathrm{eV}$ and PET corresponds in this case to the "inverted" region of the Marcus dependence, $\log k_{\text {et }}=f\left(-\Delta G^{0}\right)$. For this reason, an abrupt increase in $k_{\text {et }}^{S}$ for PdOEP$\mathrm{Ph}\left(o-\mathrm{NO}_{2}\right)$ compared to the value $k_{\mathrm{et}}^{S}=9.5 \times 10^{9} \mathrm{~s}^{-1}$ for $\mathrm{OEP}-\mathrm{Ph}\left(o-\mathrm{NO}_{2}\right)$ in toluene [20] in unlikely. As a result, upon photoexcitation, almost all $\operatorname{PdOEP}-\mathrm{Ph}\left(o-\mathrm{NO}_{2}\right)$ molecules transfer to the locally excited $T_{1}$ state because the probability of the $S_{1} \leadsto T_{1}$ conversion $r=$ $8.3 \times 10^{10} \mathrm{~s}^{-1}$ considerably exceeds the estimated rate constant of PET involving the $S_{1}$ states. One can see from the energy level diagram that the CT state of $\operatorname{PdOEP}-\mathrm{Ph}\left(o-\mathrm{NO}_{2}\right)$ in toluene is located lower by $0.05 \mathrm{eV}\left(\sim 2 k_{\mathrm{B}} T\right)$ than the $T_{1}$ state. Therefore, the lowerlying triplet state of the ion-radical pair is populated with the probability $k_{\mathrm{et}}^{T}=1.5 \times 10^{6} \mathrm{~s}^{-1}$ due to the direct PET. Because the hyperfine interaction energy in a spatially separated ion-radical pair is small (i.e., the exchange integrals are small), the singlet-triplet splitting in this pair is also small. For this reason, the ${ }^{3}$ [porphyrin $\left.{ }^{+} \ldots \mathrm{NO}_{2}^{-}\right] \rightleftarrows{ }^{1}\left[\right.$ porphyrin $\left.{ }^{+} \ldots \mathrm{NO}_{2}^{-}\right]$transitions between the triplet and singlet states of the ion-radical pair are highly efficient $\left(k_{31} \approx k_{13} \approx 5 \times 10^{7} \mathrm{~s}^{-1}\right.$ [43]). The singlet state of the ion-radical pair ${ }^{1}$ [porphy$\mathrm{rin}^{+} \ldots \mathrm{NO}_{2}^{-}$] experiences the nonradiative decay during recombination to the $S_{0}$ ground state. It is this barrier recombination process that determines the lifetime of the CT state.
Note that the lifetime of the induced absorption of $\mathrm{PdOEP}-\mathrm{Ph}\left(o-\mathrm{NO}_{2}\right)$ measured in solvents under study is determined by a complex character of the deactivation of the closely spaced locally excited $T_{1}$ state of the porphyrin and the CT state of the ion-radical pair. For this reason, the measured values of $k_{\text {et }}^{T}$ represent the effective values, which in fact reflect the fast deactivation of the $T_{1}$ state due to the direct PET to the lower-lying CT state under the conditions of the Boltzmann thermal population of these states. To elucidate the features of the direct deactivation of the locally excited $T_{1}$ state of $\operatorname{PdOEP}-\mathrm{Ph}\left(o-\mathrm{NO}_{2}\right)$ in more detail, one should perform direct picosecond kinetic measurements. Note also that the value of $k_{\text {et }}^{T}$ weakly depends on the solvent polarity. The absence of a distinct stabilization effect of the ion pair upon increasing the solvent polarity $[39,42]$ can be explained in our case by the fact that a small distance between the donor (porphyrin macrocycle) and the acceptor (nitro group) prevents the formation of individual solvates.

\section{ACKNOWLEDGMENTS}

This work was supported by the Belarussian Foundation for Basic Research, project nos. F99-104 and F98-243.

\section{REFERENCES}

1. S. Gentemann, N. Y. Nelson, L. Jaguinod, et al., J. Phys. Chem. B 101, 1247 (1997).

2. M. Ravikanth and T. K. Chandrashekar, J. Photochem. Photobiol., A 74 (1), 181 (1993).

3. C. M. Drain, S. Gentemann, J. A. Roberts, et al., J. Am. Chem. Soc. 120, 3781 (1998).

4. M. Veyrat, R. Ramasseul, I. Turowska-Tyrk, et al., Inorg. Chem. 38, 1772 (1999).

5. S. Gentemann, C. J. Medforth, T. P. Forsyth, et al., J. Am. Chem. Soc. 116, 7363 (1994).

6. S. Gentemann, C. J. Medforth, T. Ema, et al., Chem. Phys. Lett. 245, 441 (1995).

7. S. Gentemann, S. H. Leung, K. M. Smith, et al., J. Phys. Chem. 99, 4330 (1995).

8. S. Gentemann, N. Y. Nelson, L. Jaquinod, et al., J. Phys. Chem. B 101, 1247 (1997).

9. P. Charlesworth, T. G. Truscott, D. Kessel, et al., J. Chem. Soc., Faraday Trans. 90, 1073 (1994).

10. B. M. Dzhagarov, E. I. Sagun, V. A. Ganzha, and G. P. Gurinovich, Khim. Fiz. 6, 919 (1987).

11. V. A. Ganzha, G. P. Gurinovich, B. M. Dzhagarov, et al., Zh. Prikl. Spektrosk. 50, 618 (1989).

12. V. N. Knyukshto, E. I. Sagun, A. M. Shul'ga, et al., Zh. Prikl. Spektrosk. 65, 471 (1998).

13. V. N. Knyukshto, E. I. Zenkevich, E. I. Sagun, et al., Chem. Phys. Lett. 297, 97 (1998).

14. V. N. Knyukshto, E. I. Sagun, A. M. Shul'ga, et al., Khim. Fiz. 18 (5), 30 (1999). 
15. K. N. Solov'ev, M. P. Tsvirko, and V. V. Sapunov, Zh. Prikl. Spektrosk. 18, 733 (1973).

16. D. L. Eastwood and M. Gouterman, J. Mol. Spectrosc. 35, 359 (1970).

17. G. D. Egorova, V. N. Knyukshto, K. N. Solov'ev, and M. P. Tsvirko, Opt. Spektrosk. 48, 1101 (1980) [Opt. Spectrosc. 48, 602 (1980)].

18. P. J. Spellane, M. Gouterman, A. Antipas, et al., Inorg. Chem. 19, 386 (1980).

19. A. P. Losev, S. M. Bachilo, D. I. Volkovich, et al., Zh. Prikl. Spektrosk. 64, 61 (1997).

20. V. N. Knyukshto, E. I. Zenkevich, E. I. Sagun, et al., Chem. Phys. Lett. 304, 155 (1999).

21. V. N. Knyukshto, É. I. Zen'kevich, E. I. Sagun, et al., Zh. Prikl. Spektrosk. 66, 531 (1999).

22. V. N. Knyukshto, E. I. Sagun, A. M. Shul'ga, et al., Opt. Spektrosk. 88, 241 (2000) [Opt. Spectrosc. 88, 205 (2000)].

23. W.-D. Schubert, O. Klukas, N. Krauss, et al., J. Mol. Biol. 272, 741 (1997).

24. A. Harriman and J.-P. Sauvage, Chem. Soc. Rev. 25, 41 (1996).

25. A. M. Shul'ga and G. P. Gurinovich, Dokl. Akad. Nauk BSSR 25, 55 (1981).

26. K. M. Barkigia, M. D. Berber, J. Fajer, et al., J. Am. Chem. Soc. 112, 8851 (1990).

27. A. D. Adler, R. F. Longo, F. Kampas, and J. Kim, J. Inorg. Nucl. Chem. 32, 2443 (1970).

28. É. I. Zen'kevich, E. I. Sagun, V. N. Knyukshto, et al., Zh. Prikl. Spektrosk. 63, 599 (1996).

29. S. M. Bachilo, J. Photochem. Photobiol., A 91, 111 (1995).

30. A. Harriman and R. J. Hosie, J. Chem. Soc., Faraday Trans. 77, 1695 (1981).
31. M. K. Bowman, Chem. Phys. Lett. 48, 17 (1977).

32. V. V. Sapunov, K. N. Solov'ev, and M. P. Tsvirko, Zh. Prikl. Spektrosk. 21, 667 (1974).

33. General Chemistry in Formulas, Definitions, Diagrams, Ed. by V. F. Tikavyı̆ (Universitetskoe, Minsk, 1987), p. 488.

34. A. Cupane, M. Leone, E. Unger, et al., J. Phys. Chem. B 102, 6612 (1998).

35. M. P. Tsvirko, V. V. Sapunov, and K. N. Solov'ev, Opt. Spektrosk. 34, 1094 (1973).

36. G. P. Gurinovich, É. I. Zen'kevich, E. I. Sagun, and A. M. Shul'ga, Opt. Spektrosk. 56, 1037 (1984) [Opt. Spectrosc. 56, 637 (1984)].

37. V. A. Ganzha, B. M. Dzhagarov, and E. I. Sagun, in Photobiology and Membrane Biophysics, Ed. by I. D. Volotovskiǔ (Tekhnoprint, Minsk, 1999), Part III, pp. 244267.

38. E. I. Sagun, V. A. Ganzha, B. M. Dzhagarov, and A. M. Shul'ga, Khim. Fiz. 10, 477 (1991).

39. R. A. Marcus, Rev. Mod. Phys. 65, 599 (1993).

40. J. Fuhrhop, K. Kadish, and D. Davis, J. Am. Chem. Soc. 95, 5140 (1973).

41. S. L. Murrov, I. Carmichael, and G. L. Hug, in Handbook of Photochemistry (Marcel Dekker, New York, 1993), pp. 269-278.

42. G. J. Kavarnos, in Fundamentals of Photoinduced Electron Transfer (VCH, New York, 1993), pp. 287-342.

43. D. D. Fraser and J. R. Bolton, J. Phys. Chem. 98, 1626 (1994).

44. J. Liu and J. R. Bolton, J. Phys. Chem. 96, 1718 (1992).

45. D. G. Johnson, M. P. Niemczyk, D. W. Minsek, et al., J. Am. Chem. Soc. 115, 5692 (1993).

Translated by M. Sapozhnikov 